\title{
Impactos ambientales en la ciudad de Manaus: una búsqueda de comprensión
}

\section{Ambient impacts in the city of Manaus: an understanding search}

\author{
Eveline Maria Damasceno do N ascimento*1, Iraildes Caldas Torres* \\ * Universidad Federal do Amazonas, UFAM. BRASIL
}

Resumen

Fecha de recepción: 12/ 05/2008 Fecha de aceptación: 19/ 07/ 2008 PAG. $94-101$

\begin{abstract}
Este análisis está centrado en el tema titulado Impactos Ambientales en la ciudad de Manaus: una búsqueda de la comprensión nos ayudará a entender mejor la importancia de una gestión compartida con énfasis en la corresponsabilidad en la gestión del espacio público y en la calidad de vida urbana, y a que se estimulen cada vez más acciones preventivas, sin descuidar la necesidad de lidiar con las acciones correctivas. El modelo de desarrollo que ha caracterizado nuestra civilización en los dos últimos siglos conduce irremediablemente a la situación de degradación ambiental de nuestras ciudades. Este estudio analiza las implicaciones ambientales que afectan la ciudad de Manaus, generados por la no preservación de su espacio natural. El proceso de reproducción del espacio urbano nos coloca frente a transformaciones profundas porque cada sujeto se sitúa en un espacio y eso determina, al nivel de vida cotidiano, la construcción colectiva de la ciudad. Esto refuerza la necesidad de identificar los papeles y las responsabilidades de los diversos actores de cara a los temas ambientales, y la necesidad de construir consensos en torno de ellos. Se buscó adoptar una metodología dialéctica que permitió establecer un diálogo para comprender en fenómeno en cuestión. Se tornó fundamental percibir y articular la investigación en las dimensiones políticas, cultural y social y educativa que componen la visión del mundo de los habitantes de la ciudad. Los procedimientos técnicos operativos incluyeron un conjunto de instrumentos de orden cualitativa y cuantitativa compatibles y complementares que permitieron la aprensión, organización y sistematización de los datos de la investigación. Para consolidar esta discusión, entendemos que el estudio, aunque marcadamente ambiental, no es una visión ecológiconaturalista. Se busca a partir de una reflexión lúcida de la relación del espacio urbano, comprender el proceso de producción de lo urbano, su relación con el ambiente natural donde el hombre se integra como un ser que por naturaleza produce culturas.
\end{abstract}

Palabras Clave: Manaus, región amazónica, desarrollo sustentable, espacio urbano, medio ambiente, degradación

Abstract

This analysis, focused on the ambient impacts in the city of Manaus: a search for understanding, will contribute to discussions concerning the importance of a management shared with emphasis in the co-responsibility of the public space and also in the quality of urban life in order to stimulate, preventive actions increasingly, without neglecting the necessity of dealing with the corrective ones. The development pattern that has characterized our civilization in the two last centuries leads irremediably to the situation of the current environmental degradation in our cities. This study deals with the environmental implications that affect the inhabitants of the city of Manaus around the municipal park of the Mindu as a result of the lack of preservation of the natural space. The process of reproduction of the urban space leads us in front of deep transformations because each citizen points out in to a space wich determines, in the level of the daily life, the collective construction of the city, what it strengthens the necessity to identify the roles and the responsibilities of the diverse actors in face to the environmental issues and to the necessity reading consensus around them. Search to adopt a dialectical approach that allows a dialogue with various skills to understand the phenomenon in question. It is essential to articulate the search for political, cultural, social, and educational vision that comprise the world of the residents living around the municipal park of Mindu. The technical procedures include operating a set of qualitative, quantitative, compatible and complementary instruments to obtuin, organize and systematize data in the study. To consolidate this discussion, we understand that the study, although strongly environmently, is not an ecological-naturalist vision. It is supposed to from a discerning reflection of the relation of the urban space, to understand the process of production of the urban issues, its relation with the natural environment where the man inserts himself as a being that produces cultures.

Keywords: Manaus, amazon region, sustainable development, urban space, degradation

\section{Introducción}

La población mundial pasó por un acelerado proceso de urbanización en el siglo XX. El crecimiento de las ciudades se ha dado, en general, de la forma más desordenada posible, causando una serie de impactos (Guerra y

\footnotetext{
${ }^{1}$ Autor de correspondencia / Corresponding author:

Av. Gen. Rodrigo O ctávio Jordão Ramos 3000, Campus U niversitário,

Reitoria. Bairro Coroado I. CEP 69077-000, Manaus / AM. Brasil.

Teléfono: 55644 1043, E-mail: ev_am@hotmail.com
} 
Cunha, 2001) $)^{1}$ al ambiente. Esos impactos traen varios perjuicios al ambiente urbano y a los propios habitantes de la ciudad.

Manaus, localizada en la región N orte de Brasil y capital del Amazonas, es el mayor Departamento brasilero, con un área de $11.401 \mathrm{Km}^{2}$ y de clima ecuatorial es considerada el portón de entrada para la mayor reserva ecológica del planeta: La Selva Amazónica. El nombre "Manaus" es originado de la tribu Manaós, que habitaba la región. Su nombre significa "Madre de Dios". La ciudad comenzó a ser colonizada en 1669, como un pequeño fuerte en piedra y barro con cuatro cañones, Ilamado Fuerte de San José de la Barra del Río N egro. En torno de este fuerte, nació el pueblo que dio origen a la ciudad de Manaus (ver Figura 1). En 1833 pasa a la categoría de Villa, con el nombre de Manaus. El 24 de 0 ctubre de 1848 recibe el título de ciudad, tornándose la capital de la provincia del Amazonas.

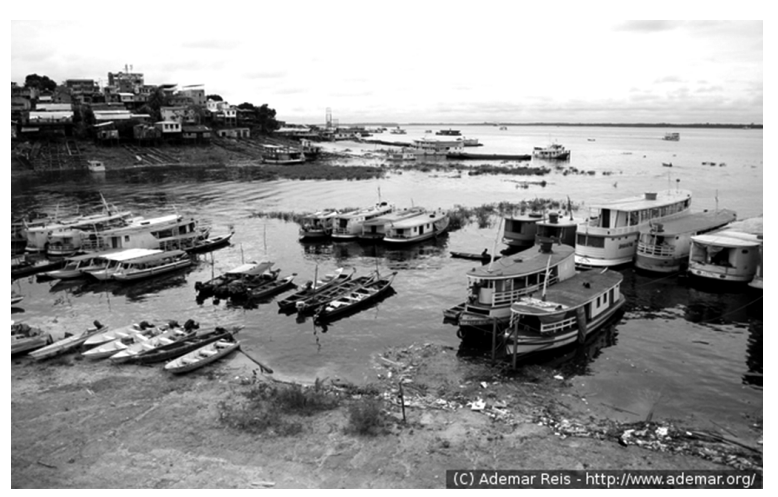

Figura 1. Puerto de Manaus (centro)

Santos (1994) nos brinda una rica comprensión sobre la ciudad. El autor sustenta la tesis de que la ciudad (C.F. Ana Fani, 1992)2 es el lugar donde el mundo se mueve más y los hombres también. Por eso, la ciudad es el lugar de la educación y de la reeducación. Cuanto más grande es la ciudad, más vasta y densa la presencia compartida y también mayores las lecciones y el aprendizaje.

Ese autor nos ayuda a comprender la ciudad no solo como producto social, sino también como construcción social en todas sus dimensiones.

Calvino (1990) relata que en toda su extensión, la ciudad parece continuar a multiplicar su repertorio de imágenes: sin embargo, no tiene espesor, consiste solamente en un lado por fuera y un reverso, como una hoja de papel, con una figura aquí y otra allí, que no pueden separarse ni encararse.

Para el autor la mejor idea es recorrer las ciudades no físicamente, sino con el pensamiento, pues la travesía no es física, sino interior. Para conocer y entender las ciudades es necesario mantener el espíritu en movimiento, la mirada siempre nueva, investigativa, procurando descortinar el aquí, pero también el allí, el otro lado, el atrás, el más allá.

\section{Espacio urbano de Manaus}

La ciudad de Manaus comprende momentos diversos en la producción del espacio. Para Oliveira (2003) el proceso de producción del paisaje urbano es continuo y discontinuo en el espacio y en el tiempo. El continuo-discontinuo afecta las relaciones sociales que se concretizan en espacialidades. A lo largo del proceso de desarrollo urbano, algunas formas desaparecen, otras se transforman y/o son recuperadas pasando a tener nuevos contenidos, sin que pierdan algunas de las características pretéritas.

Nótese que la naturaleza contribuye para la morfología de la ciudad de Manaus que se reproduce, produciendo cambios en la esencia material de la ciudad, presentando síntoma de desarrollo desigual.

El autor señala que el análisis del Manaus de hoy, solo es posible con la comprensión clara de como sus formas pretéritas se reflejan en las formas presentes. Identificar los proyectos implementados en la ciudad y las transformaciones y permanencia ocurridas son desafíos que nos posibilitan entender el tema espacial de la ciudad.

Para el autor, comprender la transformación es reconstruir los escenarios de una realidad que en parte se desvaneció.

El proceso de expansión del área urbana de Manaus (ver Figura 2), ocurrió de forma desordenada debido al alto crecimiento demográfico de la ciudad, y con eso, la expansión demográfica causó grandes impactos al medio ambiente. La trayectoria de evolución de la urbanización en Manaus en los últimos 20 años ha sido el gran desafío en el proceso de crecimiento contra la preservación ambiental.

Es válido considerar que en el área urbana del

\footnotetext{
1 El impacto ambiental es indivisible, en el nivel de avance de ocupación del mundo, se torna cada vez más difícil separar impacto biofísico del impacto social. En la producción de los impactos ambientales, las condiciones ecológicas alteran las condiciones culturales, sociales e históricas, y son por ellas transformadas. Como un proceso en movimiento permanente, el impacto es al mismo tiempo, producto y productor de nuevos impactos. Como producto actua como nuevo condicionante del proceso en el momento siguiente. Es importante considerar que las nuevas condiciones no permanecen idénticas a aquellas del inicio del proceso.

Para Ratzel una ciudad es una reunión durable de hombres y habitaciones humanas que cubre una gran superficie y se encuentra en el cruzamiento de grandes vías comerciales. Ya para Wagner, las ciudades serán puntos de concentración del comercio humano. Para Brunhes, existe ciudad cada vez que la mayoría de sus habitantes emplean su tiempo en el interior de la aglomeración.
} 
Municipio de Manaus se concentra el $99 \%$ de la populación residente, ocupando, en términos espaciales, apenas el $4 \%$ de la extensión territorial municipal, lo que indica una elevada concentración demográfica.

El avance desordenado de la ciudad principalmente en dirección a las zonas Este y Norte, provocaron pérdidas al medio ambiente sin precedentes y una serie de impactos han sido registrados. Para citar un ejemplo, tenemos las deforestaciones que no llevan en cuenta la susceptibilidad de los suelos y sus procesos erosivos. Se suma a esto el hecho de que la deforestación asociada a las construcciones de edificios y el surgimiento de calles y avenidas causan degradaciones, haciendo que las inundaciones sean cada vez más constantes en las ciudades; la destrucción de nacientes de agua, la amenaza de extinción de especies animales nativas, la mayor vulnerabilidad a problemas de erosión, anegamientos y aumento de temperatura ocasionado por el desaparecimiento de especies vegetales que tienen como función proteger el suelo de las agresiones del Sol y de la lluvia, etc. Lo que quedó en la zona urbana de la ciudad fueron fragmentos forestales que se localizan dispersos y en su gran mayoría sin utilidad para las comunidades que los rodean.

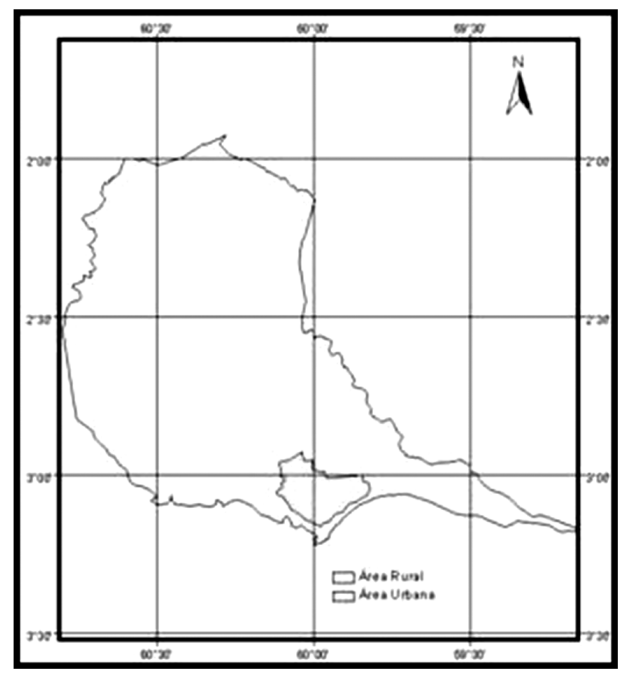

Figura 2. Manaus - Zonas U rbana y Rural Fonte: José Aldemir de O liveira (2007)

M anaus también sufre con los temporales, que en pocos minutos provocan el anegamiento de sus calles y la destrucción de casas. El volumen del agua que cae, no teniendo por donde ser canalizado, va acumulándose exponencialmente. Y el agravante es que la continuidad del crecimiento desordenado podrá acabar por no viabilizar el proceso de modernización de la ciudad de Manaus.

Guerra y Cunha (2001), Ilegan a un consenso sobre el concepto de impacto ambiental afirmando que, impacto ambiental es, por lo tanto, el proceso de cambios sociales y ecológicos causado por perturbaciones (una nueva ocupación y/o construcción de un objeto nuevo: una usina, una carretera o una industria) en el ambiente. Dice todavía respecto a la evolución conjunta de las condiciones sociales y ecológicas estimulada por los impulsos de las relaciones entre fuerzas externas e internas de la unidad espacial y ecológica, histórica o socialmente determinada. Es la relación entre sociedad y naturaleza que se transforma diferencial y dinámicamente. Los impactos ambientales son escritos en el tiempo e inciden diferenciadamente, alterando las estructuras de las clases sociales y reestructurando el espacio.

Esos procesos provocan desequilibrios ambientales, sociales y culturales que tienen fuertes interferencias en la vida de las poblaciones locales. U no de los fuertes impactos ocurrió por ocasión de la economía gomífera que trajo grandes contingentes de nororientales para las caucherías amazónicas y que, después del ocaso de las actividades de la Hevea brasiliensis, muchos de ellos vinieron para Manaus acabando por provocar el "hinchamiento" abrupto de la ciudad. Lo mismo ocurrió con el proyecto Zona Franca de Manaus (La ZFM es lanzada oficialmente en 1957, pero en 1967, por el Decreto-Ley $\mathrm{N}$ 288, de febrero, el gobierno federal amplio la legislación de creación y reformuló el modelo, estableciendo incentivos fiscales por 30 años para implementación de un polo industrial, comercial y agropecuario, teniendo como centro la capital amazonense. En este mismo año, para administrar la ZFM fue creada la Superintendencia de la Zona Franca de M anaus-SU FRAMA), que promovió un extensivo éxodo rural, instigando la venida de muchos otros brasileros para la industria de productos semiestructurados. La ciudad es una realización humana, una creación que se va constituyendo a lo largo del proceso histórico y que gana materialización concreta, diferenciada, en función de determinaciones históricas específicas. Actualmente muchos autores afirman que el mundo se torna urbano debido al rápido crecimiento de las ciudades modernas y a la transformación de vastas áreas en aglomerados urbanos. 


\section{La visión de los habitantes de la ciudad de manaus}

Los habitantes son los principales actores sociales que establecen relaciones entre si con la naturaleza y la sociedad por intermedio del trabajo y/o de la ocupación que ejercen.

Fueron aplicados 12 formularios a los residentes de la ciudad: 6 hombres y 6 mujeres, siendo 3 hombres y 3 mujeres provenientes de conjuntos residenciales en barrios privilegiados y 3 hombres y 3 mujeres de residencias en situaciones precarias para percibir el nivel de conciencia ambiental o no de las poblaciones locales.

La observación fue un recurso importante para la identificación de la dinámica organizacional local en el ámbito social, cultural y político de los residentes, con el fin de desenmascarar los impedimentos, así como las estrategias para posibles soluciones a dichos problemas.

Uno de nuestros entrevistados nos habló de su experiencia en la ciudad y como se sentía siendo residente de Manaus. Él se expresó así “Manaus está creciendo demasiado, y no está pudiendo resolver tantos problemas sociales, el transporte está caótico, no hay buses suficientes para todas Ias rutas; la basura está adueñándose de algunos barrios, la atención hospitalaria es un caos; sin embargo, a pesar de tantos problemas, Manaus continúa siendo la ciudad sonrisa, es hospitalaria, absorbe una gran cantidad de personas y es conocida por la facilidad de empleo. Pienso que si la sociedad se organizara de forma colectiva, consecuentemente sería más fácil alcanzar esa meta. Pues esta ciudad es soñada por muchos, porque a pesar de sus problemas ella todavía encierra paz y cierta seguridad y una naturaleza espectacular". (A. E. G es residente en Manaus y fue entrevistada por la investigadora en Noviembre de 2007).

Relatos como este son comunes en las entrevistas y esto nos lleva a pensar que, a pesar de los choques y contradicciones tramados en el espacio urbano, los habitantes demuestran empatía por la ciudad (Figura 3). Del mismo modo que existe formas de entendimiento de la ciudad, creación de imágenes de la ciudad, también existen formas de ruptura y los habitantes perciben que la ciudad es también un campo privilegiado de luchas de clase y movimientos sociales de toda especie, que cuestionan la normalización de la ciudad y de la vida urbana.

La ciudad es una producción y/ o construcción humana que reúne las culturas, los sentimientos, las representaciones del imaginario social, los conflictos, las clases y todos los otros elementos de las relaciones del cotidiano. Esto implica un esfuerzo en la comprensión de la complejidad de las relaciones hombre y medio; naturaleza y relaciones sociales; región y sitio, en una dimensión exenta de cualquier connotación de tribu, el de grupo lingüístico, nación, lugar y mundo. Implica, eso sí, la comprensión de las relaciones entre Gobierno y sociedad; empresas privadas y sociedad; empresas gubernamentales y de economía mixta y sociedad; empresas públicas y privadas en interlocución con la sociedad, tercer sector y sociedad local.

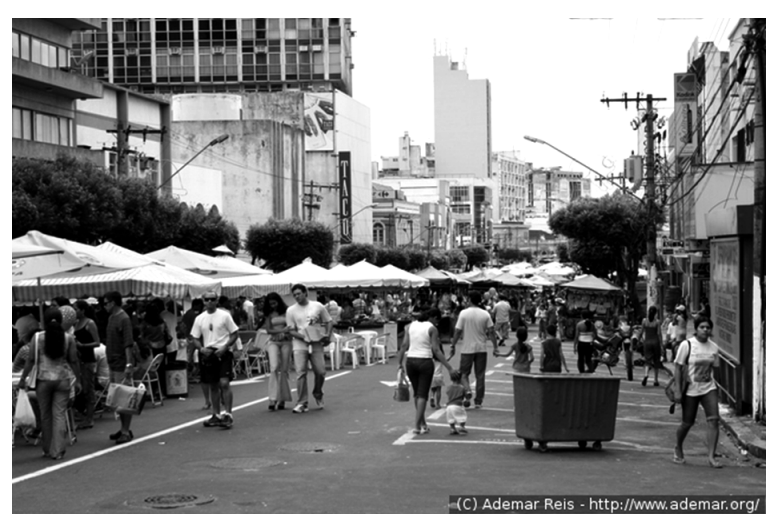

Figura 3. Centro de la cuidad de Manaus Fuente: Foto de Ademar Reis

Es en este escenario que la ciudad se coloca como el espacio de la producción de los conflictos y de las sangrías desatadas que se establecen en medio a los intereses antagónicos. La ciudad es el palco de la lucha de clases, siendo pues el Estado la instancia mediadora de las contiendas sociales capaz de pactar las relaciones de conflicto, colocándolas en niveles seguros sin retirar de los individuos el derecho a la ciudad. Para Lefebvre (1969) la reivindicación de la naturaleza, el deseo de aprovecharse de ella son desvíos de derecho a la ciudad. Esta última reivindicación se anuncia indirectamente, como tendencia de huir a la ciudad deteriorada y no renovada, la vida urbana alienada antes de existir realmente.

El derecho a la ciudad no puede ser concebido como un simple derecho de visita o de retorno a las ciudades tradicionales. Solo puede ser formulado como derecho a la vida urbana. Transformando, renovada.

La situación de las ciudades del Amazonas marcada por la invisibilidad y segregación socio-espacial fue inducida por un Departamento que, en el pasado, invirtió pesadamente en el fomento y estructuración de un desarrollo urbano industrial, vuelto para las necesidades productivas del capital y para el consumo de las clases hegemónicas.

Las políticas concentradoras de renta en 
detrimento de la inversión en políticas públicas ostentan un cuadro de déficit habitacional y de precariedad de los servicios de educación, saneamiento básico, atención médica, transporte, guarderías y abastecimiento de agua en las áreas periféricas de la ciudad.

El análisis de impactos merece examen minucioso de elementos de la ciudad que incluyen localizaciones, las distancias, las condiciones ecológicas, el acceso diferencial a la tierra, las acciones y formas de apropiación social de los espacios de la ciudad.

La concentración urbana en la ciudad de Manaus y su desarrollo han sido realizados de forma poco planeada, en medio a conflictos institucionales y tecnológicos. La tendencia actual de este tipo de planeamiento urbano está llevando las ciudades a un caos ambiental con costo extremadamente alto para la sociedad. La visión limitada de tratar los procesos de forma aislada o compartida es una de las primeras causas de los problemas provocados. Es necesario tratar esos problemas de forma interdisciplinar. La minimización y el control de los problemas relacionados con los impactos ambientales son interdisciplinares y exigen diferentes visiones para buscar soluciones adecuadas.

Es en este escenario que la ciudad se coloca como el espacio de la producción de los conflictos que se establecen en medio a los intereses antagónicos. La ciudad es el palco de la lucha de clases y, el Estado es la instancia mediadora de las contiendas sociales, capaz de pactar las relaciones de conflicto y el contrato de convivencia colocando en niveles seguros sin retirar de los individuos el derecho a la ciudad. Carlos (2001) resalta que la construcción de un pensamiento sobre la ciudad reposa en la necesidad de elaborar la problemática urbana, que se revela en una articulación que ilumina las relaciones entre la ciudad y lo urbano. Diferentemente de la práctica socio-espacial, la problemática urbana se construye en el plano teórico.

Para esta autora habitar la ciudad es tejer por sus idas y venidas diarias una red de hilos entrelazados de recorridos generalmente articulados en torno de algunos ejes directores.

\section{Impactos ambientales}

En este sentido, podemos aprender valiosas lecciones extraídas del estudio de ecosistemas, que son comunidades sostenibles de plantas, de animales y de microorganismos. Para comprender esas lecciones, necesitamos tornarnos, por así decir, ecológicamente alfabetizados. Ser ecológicamente alfabetizado significa entender los principios de organización de las comunidades ecológicas (ecosistemas) y usar esos principios para crear comunidades educativas, comerciales y políticas de modo que los principios de la ecología se manifiesten en ellas como principios de educación, de administración y de política (Capra, 1996)

Guerra y Cunha en sus estudios sobre impactos ambientales tejen comentarios afirmando que, de un modo general, los estudiosos de impactos ambientales, están más preocupados con la identificación de los efectos inmediatos y locales de que con el estudio y la interpretación de los procesos. Para esos autores, la base de la problemática está, en la posibilidad de superar la visión estático-convencional de impactos ambientales y en la necesidad de avanzar en dirección a las teorías de los procesos de cambios que resulta de la interacción de los procesos biofísicos, político-económicos y socioculturales, de una misma ciudad y de una formación social (Guerra y Cunha, 2001).

Crecen, así, las demandas por la participación en las decisiones y acciones por parte de los actores sociales, con el fin que la gestión de los problemas ambientales urbanos pueda ser una construcción social donde el Estado-Gobierno divida con la sociedad civil las responsabilidades de las decisiones y de las ejecuciones.

De esa forma, en la construcción de un mapa urbano dinámico de exclusión social no pueden ser ignoradas ni las condiciones ecológicas (locales y regionales) ni las condiciones de segregación social dinámicas que influyen en la construcción de los diversos ambientes urbanos.

La complejidad de los procesos de impacto ambiental urbano presenta desafíos. Por un lado, es necesario problematizar la realidad y construir un objeto de investigación. Por otro, es necesario articular una interpretación coherente de los procesos ecológicos y sociales concernientes a la degradación del ambiente urbano. Se hace necesario promover la división en zonas ecológico-económicas como prioridad y condición básica para la reorganización de su espacio y estandarización de modelos compatibles con la preservación y conservación ambiental.

En las últimas décadas, procesos desenfrenados de desarrollo económico han sido responsables por pérdidas significativas en la diversidad biológica, resultantes de la ocupación y destrucción de ecosistemas hasta entonces intocados por la acción del hombre. El desafío a ser enfrentado es el del desarrollo de un modelo de consumo 
sostenible de los recursos naturales, que permita no solamente el desarrollo social y económico de la región, sino también la preservación del ecosistema.

El debate sobre el tema del desarrollo viene siendo tramado hace algunas décadas. Su intensificación más reciente está asociada a los drásticos cambios políticos que el mundo occidental ha enfrentado con fuerte exasperación de las tensiones sociales de cara a la incesante degradación del medio ambiente (Oliveira, 2003)3

Torres (2005) sustenta que la ciudad es un elemento civilizador cuyo origen civita significa civilizado que es el pueblo que vive en ella y la respeta. No se puede dar crédito únicamente a la ciudad el corolario de la barbarie y de la degeneración humana, aunque la producción de la pobreza y de la miseria no pueda prescindir de ella. Los destinos de la ciudad dependen de la acción de las fuerzas políticas en presencia, no es una estructura amorfa y estancada. Ella es paradójicamente el espacio de irradiación de acciones que plenifican la vida, y el espacio de producción de muerte o de acciones que impiden el desarrollo humano.

En este sentido, para comprender la ciudad se hace necesario traer esa perspectiva humana que no se puede querer entender la ciudad si no por las personas que la hacen; a partir de sus vivencias, a partir de sus valores, su cultura, en fin, si queremos comprender la ciudad es necesario ver fundamentalmente hacia las relaciones sociales ahí establecidas, pues la ciudad es palco y resultado de esas relaciones.

Conviene observar, sin embargo, como registra Capra (1996) en su libro A Teia daVida (1996), que "cuanto más estudiamos los principales problemas de nuestra época, más somos llevados a percibir que ellos no pueden ser entendidos aisladamente y que hay soluciones para los principales problemas de nuestro tempo, algunas de ellas hasta simples".

Este autor afirma que el reconocimiento de que es necesario un profundo cambio de percepción y de pensamiento para garantizar nuestra sobrevivencia todavía no ha alcanzado a la mayoría de los líderes de nuestras corporaciones, ni a los administradores y profesores de nuestras grandes universidades.

La realidad ha demostrado que al menos hasta el presente momento, los beneficios alcanzados no han sido suficientemente compartidos con las poblaciones locales. Muchos problemas graves que podrían ser superados a través del uso de conocimientos ya existentes continúan afectando a la región por cuenta de políticas que no incorporan la ciencia en su formulación.

Manaus trae en la estructuración de su espacio y de su población, las marcas de esa acelerada y desmesurada urbanización (ver figura 4), perceptible en los barrios que componen la ciudad.

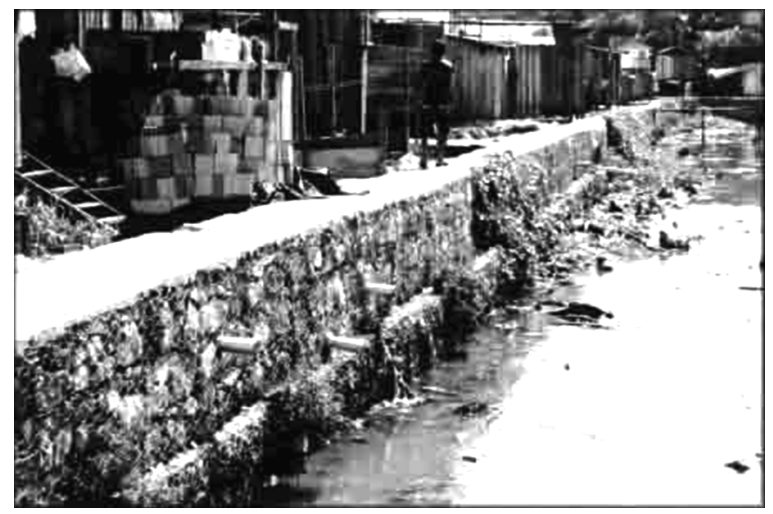

Figura 4. Tuberías de alcantarillado doméstico/sanitario. Igarapé de São Francisco.

Fuente: Foto de Dayson Jardim-Lima/U N IAMBIENTE

Esta foto refleja las alteraciones ocurridas en las diferenciadas formas en que se presenta el proceso de acumulación capitalista en la ciudad de Manaus y va siendo también el proceso de degradación del medio ambiente, por la ausencia de infraestructura básica de alcantarillado, transformándoles en espacio agresivo para las poblaciones que ahí residen.

En conversación con los residentes se percibe la insatisfacción en relación a su situación socioeconómica, a la actuación del poder público Municipal y en relación al ambiente en que construyen su diario vivir. Esto muestra que los habitantes tienen consciencia de las causas políticas y sociales que implican en el fenómeno de la degradación ambiental, los cuales dejan claro que solo será posible el cambio, si los poderes públicos y los gobernadores cambiasen su forma de administrar la ciudad.

Una de las entrevistas que sobresalió fue:

Para mí, yo veo que esa ciudad es una ciudad muy buena para vivir, lástima que es calurosa, porque viví dos años en Río de Janeiro. Están haciendo una cosa bonita, sacando a los habitantes de las márgenes de los albañales por el Prosamim (El Programa Social e Ambiental dos Igarapés de Manaus - PRO SAM IM tiene como objetivo, mejorar la calidad de vida de la

3 Oliveira señala el hecho de que el medio ambiente es construido por la relación de la sociedad con la naturaleza por medio del trabajo, por tanto, es producción social. Así, él es continuamente mudable. Muchas veces las transformaciones ambientales que ocurren por medio del trabajo, rompen la cadena trófica e introducen componentes que antes no existian en la naturaleza. El resultado de ese proceso se expresa en la reducción, perdida o hasta el mismo desaparecimiento de propiedades, más allá de la calidad o capacidad productiva de los recursos naturáes en vista de las variadas formas de polución y producción de un ambiente nocivo que afecta directa o indirectamente la salud y la seguridad 
población residente en el área de abarcamiento del Programa, a través del mejoramiento de las condiciones de salud y del entorno urbano), pero no sé como va a quedar, hay que mirar con más cuidado la ciudad. A mí me gustan los puntos turísticos, pero aquí las cosas son muy caras y la gente ensucia la ciudad, ellos ven el anuncio de no arroje basura aquí, pero así mismo botan basura, esas personas deberían ser multadas, pues los perros cogen la basura y despedazan todo, pero pienso que la alcaldía debería mejorar en relación a la limpieza, limpiar los arroyos (...) Sin embargo a mí me gusta mucho aquí por las quebradas de los ríos. El encuentro de las aguas es absolutamente bonito, y andar en barco es muy chévere. (ENTREVISTA / L.F - 05/09/2007).

Por la declaración de la entrevista mencionada, se nota la concientización ambiental de este habitante acerca de la ciudad. En parte de la afirmación de que es importante la preocupación con la ciudad y que ésta necesita de cambios para preservar sus recursos naturales $y$, al mismo tiempo, posibilitar un desarrollo social justo, permitiendo que las sociedades humanas alcancen una mejor calidad de vida en todos los aspectos.

Este discurso está presente y puede ser considerado como una síntesis de los demás entrevistados que respondieron esta cuestión sobre la ciudad de Manaus, relacionando la mejoría de la ciudad con la calidad de vida de los habitantes. U no de los matices presentes en estos discursos habla de la necesidad de una consciencia ambiental más actuante para que conjuntamente con el poder público se pueda mejorar la ciudad.

El concepto de desarrollo sostenible es heterogéneo y ambivalente. Para Sachs (2004), este concepto encuentra sustentación en cinco pilares, a saber:

1) Sostenibilidad social que dice respecto a la equitativa distribución de renta

2) Sostenibilidad económica asociada al principio de solidaridad entre las poblaciones locales para mejorar el uso de los recursos y generación de renta colectiva;

3) Sostenibilidad ecológica dirigida al uso racional de los recursos naturales del ecosistema;

4) Sostenibilidad geográfica relativa a los cuidados ambientales y espaciales para evitar desastres y daños a la región;

5) Sostenibilidad cultural que envuelve el concepto de territorio en cuanto espacio de construcción de posibilidades al desarrollo regional, llevándose en consideración los saberes, valores y potencialidades.

Además conlleva a una ruptura del paradigma como las representaciones dominantes sobre desarrollo. De acuerdo con Castro y Pinton (1997), se traduce, más precisamente, la necesidad de ultrapasar la dicotomía instaurada entre naturaleza y sociedad como medio de reconciliar preservación del medio ambiente y desarrollo económico y social. Sin embargo, confrontar, en escala planetaria la problemática sobre el medio ambiente con la cuestión del desarrollo no es un emprendimiento de fácil alcance cuando se sabe que ningún modelo, hasta el presente, fue susceptible de satisfacer a esas exigencias.

Cualquier propuesta de desarrollo deberá llevar en consideración la calidad ambiental, estimulando las inversiones en las áreas más adecuadas inhibiendo el programa de alto riesgo económico, social y ambiental.

Innumerables y graves son los problemas que afligen tanto las poblaciones urbanas como los pueblos tradicionales. El modelo de desarrollo posible de ser implementado en la región deberá tener como hilo conductor la cuestión étnica. El crecimiento económico deberá tener como base inductora la potencialidad de la capacidad de las poblaciones tradicionales, a partir de una ética de desarrollo social que remita hacia el contorno de las desigualdades regionales y de los impactos ambientales. De forma paralela y similar, al lidiar con cuestiones regionales, comúnmente el proceso de formulación de políticas no tiene en cuenta el conocimiento científico disponible, en la búsqueda por soluciones racionales para los problemas.

Sachs (2004), enfatiza que el crecimiento aunque acelerado, no es sinónimo de desarrollo si no reduce la pobreza y si no atenúa las desigualdades y también exige que se evite la trampa de la competitividad ilegítima y, en última instancia, autodestructiva, con base en la depreciación de la fuerza de trabajo y de los recursos naturales.

En esta perspectiva, valiéndose de los trabajos más recientes de Capra, podemos decir que "reconectarse con la tela de la vida significa construir, nutrir y educar comunidades sostenibles, en las cuales podamos satisfacer nuestras aspiraciones y nuestras necesidades sin disminuir las chances de las generaciones futuras".

Por fin, podríamos concluir afirmando, a partir de Marx, que "El hombre vive en la naturaleza y esto significa que la naturaleza es su cuerpo, con el cual él debe permanecer en continuo relacionamiento si no quiere morir. Que la vida física y espiritual del hombre está vinculada a la naturaleza significa, simplemente, que la naturaleza está vinculada a sí misma, pues el hombre es parte de la naturaleza" (Capra 1996).

Así, las implicaciones ambientales que afectan a Manaus no pueden prescindir de la investigación de emprendimientos científicos que fundamenten estrategias Sachs (2004). 


\section{Conclusiones}

En esa perspectiva, se evidencia que Manaus no es más la misma, y este cambio hace que referenciales sean perdidos, valores sustituidos y que nuevas identidades sean construidas, reformulando los espacios de representaciones, o sea, los espacios vividos. Es a través del espacio de representación que se puede tener una comprensión de la ciudad en su interior, y hacer de ella una lectura, pues es en ella donde mejor se observa como se dan las relaciones en la sociedad, principalmente las que no están establecidas objetivamente.

Cualquier perspectiva de desarrollo para la región debe estar racionalmente articulada con el paradigma de la sostenibilidad. Esto no quiere decir que la sostenibilidad deba determinar los rumbos a ser seguidos. Se quiere reafirmar la necesidad de la comunidad científica interferir procesos de formulaciones de políticas y en los rumbos de las decisiones, incluyendo la articulación con los organismos internacionales en la búsqueda por soluciones plausibles para los problemas y las demandas de la sociedad.

Este escenario muestra una realidad no solo de la Amazonía, mostrando también la de otros Departamentos del Brasil. Y éste es el desafío de nuestro tiempo: crear comunidades sostenibles que posibiliten la emergencia de experimentos de modelos de desarrollo económico más integrados a las realidades regionales y comprometidos con la preservación ambiental, o sea, ambientes sociales y culturales donde todos puedan satisfacer las necesidades y aspiraciones sin disminuir y/o comprometer el usufructo de estos bienes a las generaciones futuras.

La construcción de políticas públicas constituye una demanda imperiosa para evitar el desperdicio de los recursos públicos y estimula los procesos de desarrollo sostenible medio ambiente. Es importante el envolvimiento de las comunidades locales en esas acciones en la medida en que enriquece el debate y el nivel de sensibilización popular para la conservación, buscando construir estrategias conjuntas para el enfrentamiento de los problemas existentes.

Q uedó claro en este estudio que las ciudades son influenciadas por una dinámica social y contradictoria presente en el movimiento histórico de las sociedades. Se trata de componentes que articulan procesos de largo alcance, determinando cambios en los procesos sociales y ecológicos. Así, las medidas de minimización de impactos ambientales tienen que ser pensadas en una escala de acción social bien más amplia, que pueda abarcar de forma integrada, la ciudad y su espacio circundante e inmediato, y hasta espacios más distantes.
Se observa que los problemas relacionados a la cuestión ambiental en la ciudad de Manaus están lejos de ser resueltos. La solución de los problemas depende de la capacidad de organización de los habitantes, pero depende, sobretodo, de la acción del Gobierno. Las mejorías dependen del crecimiento de la economía, de la distribución de renta, de política habitacional para la población de baja renta y de crear condiciones para implementar la reforma urbana. El Impacto ambiental en la ciudad no es apenas una manifestación de las desigual dades sociales concretizadas en desigualdades socio-espaciales por la falta de servicios básicos y de derechos humanos, es también síntoma de una sociedad urbana, en que desigualdades son toleradas y en virtud de eso, proliferan.

El principal desafío que se coloca en los días actuales es que la ciudad, críe las condiciones para asegurar una calidad de vida que pueda ser considerada aceptable, no interfiriendo negativamente para evitar la continuidad del nivel de degradación, notadamente en las regiones habitadas por los sectores más carentes.

\section{Referencias}

Calvino I. (1990), As cidades invisíveis. Tradução de Diogo Mainardi. São Paulo: Companhia das Letras Castro E. e Pinton F. (1997), Faces do Trópico Ú mido - Conceito e Q uestões Sobre D esenvolvimento e M eio Ambiente. Belém: Cejup: UFPA-NAEA.

Capra F. (1996), A teia da vida U ma nova compreensão científica dos sistemas vivos. São Paulo: Cultrix.

Carlos A. F. A. (2001), Espaço - Tempo na M etrópole: a fragmentação da vida cotidiana. São Paulo: Contexto, 2001.

Guerra A. J. T. y Cunha S. B. da. (2001), Impactos Ambientais U rbanos no Brasil. Rio de Janeiro: Bertrand Brasil.

Lefvebvre H. (1969), O Direito à Cidade. São Paulo: Documentos Ltda.

Oliveira J. A. (2003), M anaus de 1920-1967, A cidade doce e dura em excesso. Manaus. Manaus: ed. Valer / Governo do Estado do Amazonas / Editora da Universidade Federal do Amazonas.

Sachs I. (2004), D esenvolvimento includente, sustentável, sustentado. Rio de Janeiro: Garamond.

Santos M . (1994), Técnica, Espaço, Tempo, Globalização e Meio Técnico-Científico Informacional. São Paulo: HUCITEC.

Torres I. C. (2005), As novas Amazônidas. Manaus: Edua. 